\title{
Autonomous Vehicles and Autonomous Driving in Freight Transport
}

\author{
Heike Flämig
}

\subsection{Introduction}

The degree of vehicle automation is continuously rising in all modes of transport both on public traffic infrastructure and in-house transport within company grounds, in order to improve the productivity, reliability, and flexibility of transport. Due to the growing information density and the complexity of the geographic division of labor, the idea of autonomous, decentralized local units is gaining in significance. By focusing on private passenger vehicles, however, public and scientific debate has until now neglected around one third of traffic on public roads, i.e. commercial traffic. Thereof, around one third is goods transportation, because the location of raw material or final goods production seldom coincides with the place of goods demand. Transport itself adds no value to the product. For this reason, applications where transport could take place without a driver were developed for in-house logistics as early as in the 1950s. The so-called driving robot was primarily developed for taking over special missions in dangerous or practically inaccessible situations. Automated, driverless and partially autonomous vehicles have therefore been in operation for transporting goods in production and logistics systems for a long time.

In essence, the question can be asked to what extent fully automated vehicles can also be meaningfully used in road freight transport on public infrastructure. This is connected to further questions such as how much sense it makes to bring in such technology, what are the necessary technological, organizational and legal conditions, but also how logistics, supply chains and freight transport may change as a result.

\section{H. Flämig ( $\square)$}

Technische Universität Hamburg-Harburg-TUHH, Institute for Transport

Planning and Logistics, 21071 Hamburg, Germany

e-mail: flaemig@tu-harburg.de 
This chapter firstly approaches these questions from the historical perspective of in-house logistics, as this provides a clear understanding of companies' motivations for implementing driverless transport systems and the individual experience of company decision-makers'. Using case studies from the field of logistics and freight transport, this chapter will examine current fields of application and, wherever possible, the navigation and safety concept required for autonomous driving as well as control. Moreover, it will outline specific use cases for freight transport based on the generic descriptions in Chap. 2. Other autonomous systems developing in parallel, such as drones, show that completely new business models are developing in the field of logistics. Expected changes in logistic processes and in human labor in the systems will be discussed using a generic supply chain approach. The chapter will conclude by making recommendations and suggestions for further research.

\subsection{Development History of Driverless and Autonomous Transport Systems}

Automated guided transport (AGT) systems and automated guided vehicles (AGVs) were firstly used for commercial purposes in the early 1950s in the US and approximately ten years later in Germany [1]. The primary motivation was optimizing the flow of materials and reducing personnel, as a logical consequence of the ideas for raising productivity through improving work processes which had been spreading since the early 19th century (Frederick W. Taylor), from the timing of production processes (shaped in particular by Gilbreth's "system of predetermined times") to continuous assembly line production (Henry Ford). This development was driven by the mechanization of production due to an increasing focus on technology by management, to the point of envisioning complete automation (see the historical development in [1]). Beginning with the automation of transfers between production processes, the first AGT systems were used in production and warehouses. Compared to automated conveyance systems, such as conveyor belts, the investments are generally significantly lower and the flexibility with regard to changes in the material flow is considerably higher [2]. Transport is regarded as an unproductive activity, but must nevertheless demonstrate high reliability in production and warehouse systems.

\subsubsection{Driverless Indoor Transport Systems}

Typical indoor applications of AGT systems connect production and assembly processes, incoming and outgoing goods areas as well as picking areas and warehouses. AGT systems and work robots, such as those for picking, palletizing, etc., are frequently combined in a single apparatus. In in-house logistics, the encounter between humans and AGT/AGV systems was therefore always envisioned since AGT/AGV systems generally 
perform other functions as well, for example supporting the picking process. Early personal safety concepts worked with tactile, mechanical bars or bumpers [2]. Today, laser scanners are more widely used which, depending on the driving speed, can cover up to $7 \mathrm{~m} \mathrm{[2]} \mathrm{and} \mathrm{are} \mathrm{frequently} \mathrm{combined} \mathrm{with} \mathrm{other} \mathrm{sensor} \mathrm{technologies.} \mathrm{The} \mathrm{stabilization}$ level plays a relatively minor role in in-house transport as the company itself maintains the floor surface in a drivable state.

In early systems, the guidance level in the indoor component of in-house transports was generally implemented with electrical conductors embedded in the floors. Today the following different types for position recognition and positioning can be distinguished [3]: On the one hand, this includes the physical guide, implemented either as an active inductive guide path, as a magnetic tape or optical guide path. On the other hand, technologies for free navigation which utilize floor markings (metal, magnets, transponders) or laser technology in which position-determination functions something like in maritime transport (cross bearing) can be found. Newer technologies combine laser scanners and camera systems with digital-environment maps and enable navigation by characteristics of the environment.

Data transmission between the stationary and mobile units of an AGT system was previously conducted using inductive or infrared data transmission. Today, narrowband and increasingly broadband transmission (WLAN) are predominant. Radio direction finding enables localization via indoor GPS (Global Positioning System) with an accuracy up to $0.5 \mathrm{~m}$, with outdoor GPS precise to within $10 \mathrm{~m}$, dGPS (Differential GPS) accurate up to $1 \mathrm{~m}$ and dGPS with phase evaluation precise to within $0.1 \mathrm{~m}$.

Vehicles are assigned to driving tasks and are coordinated [2]. The control concept consists of a control unit through which execution of the transport order, transport order processing, vehicle allocation and transport execution are managed centrally. The traffic control system is part of the vehicle job execution. Clearance for individual sections of the route is done similarly to the rail traffic system in block sections that can only be occupied by one vehicle at a time.

One such system was implemented in the distribution center of a logistics service provider in 2011 [3]. In the picking process, AGT systems are used in which the pickers are carried by the vehicle as well. The safety of the picker is ensured through various measures, as with the safety regulations for rail transport in which passengers are required to assume a particular position with their hands and feet. It is therefore not possible to carry out other activities while the vehicle is in motion. The operator safety concept relies on laser scanners. Navigation relies on a magnetic point sequence guide system, and the control system utilizes wireless-technology for data transmission.

The AGT/AGV control system is also handled centrally in the new systems. Expanding the systems is therefore always associated with major expenses, so research into autonomous, decentralized control solutions is afoot here as well.

One current example is the autonomous reach forklift truck developed in the "marion (mobile, autonomous, cooperative robots in complex value creation chains)" project, which in turn was developed as part of the "Autonomik" (autonomous and 
simulation-based systems for SMEs) technology program. The tasks of vehicles are assigned by a superordinate system. The forklift executes the task autonomously and calculates and determines the optimal route independently. It is equipped with a 3D-laser, laser scanner and cameras for 3D environment detection. Through sensors, the forklift can precisely assess the environment, the object dimensions and its spatial position.

One example of a decentralized control system has been developed in the project "decentralized, agent-based self-control of automated guided transport systems" [4]. In this system, various agents are modeled for each vehicle. Route planning and task assignment take place cooperatively. Simulations showed a reduction in the overall route distances of all AGVs, a roughly $8 \%$ drop in the empty trip share, a $22 \%$ decrease of lead times and a minor increase of the utilization rate of the AGVs [5]. At the Fraunhofer-Institute for Material Flow and Logistics (IML), a cellular transport system based on swarm intelligence was developed in the "Swarm Intelligence for Logistics" project. In this system, the swarm (the means of transport) receives the transport jobs, the nearest vehicle takes on the job and dynamically determines the shortest path.

\subsubsection{Outdoor Automated Guided Vehicles on Private Property}

Outdoor applications for autonomous vehicles on private property are AGT systems for heavy transports or in-plant shuttle traffic are common, as the following examples demonstrate.

At a container terminal, automated guided vehicles move containers between the container cranes and the stacking area [6]. The objective is to shorten routes, reduce empty trips and achieve optimal utilization of all resources. Transponders installed in the ground are used for positioning. Route planning is done independently, as are battery changes. Coordinating control is conducted via radio data transmission.

In Germany, a major cooperation behind driverless trucks is a company that was originally active in the radio technology sector. In 2012, for example, this company implemented a driverless truck-shuttle between the production and logistics buildings on the factory grounds of a dairy company [7]. Loading and unloading of the pallets laden with fresh products and packaging materials are done automatically. The lane-guidance system utilizes transponders in the pathway. A sensor is installed beneath the towing vehicle that uses the markings on the floor for orientation and route determination. Aided by steering rear axles, the vehicles can drive small envelopes and achieve positioning precision to within $2 \mathrm{~cm}$. Laser scanners scan the environment and together with contact switch strips and emergency stop buttons ensure the safety of people, goods and the vehicle itself.

The "Sichere autonome Logistik- und Transportfahrzeuge (SaLsA)" ["Safe autonomous logistics and transport vehicles"] project led to further developments that made the encounter between AGT systems, trucks and people in the outdoor environment safer [8]. In the outdoor environment, the safety concept consists of radar sensors, since laser 
scanners are not permitted there. The cooperative scanning of the environment through mobile and stationary sensors enables safe operation even at higher speeds (economic viability).

\subsubsection{Autonomous Vehicles for Road Freight Transport Outside of Plant Grounds}

The development of autonomous vehicles for freight transport and logistics outside of plant grounds is primarily conducted on a problem-oriented basis. So called driving robots were developed for use in dangerous situations, e.g. for disarming munitions, or for use in difficult-to-access areas such as deep-sea exploration, work on mountain sides or in dense forests and remote areas such as for work in the mining sector.

Very large automated trucks with a maximum load capacity of 290 metric tons have been used at one of the world's largest iron-ore mines in Australia since the 1990s [9]. The reason for their development was primarily difficulties in staffing, the dangerous shift work in the outback and the demanding logistical requirements in terms of personnel planning and staff transfer.

Navigation is done via radar and lasers as well as through the use of waypoints for orientation. Monitoring and intervention options are possible via an operation center using wireless transmission. Control is carried out via GPS and dead reckoning, such as in ships or aircraft, through continuous position determination by means of measuring the course, speed and time.

\subsubsection{Development of Autonomous Driving and Autonomous Vehicles in Other Means of Transport}

Other means of transport, in which technical systems for stabilization, navigation (e.g. digital maps) and environment cognition are used have also seen increasing degrees of automation.

Aircrafts have been equipped with stabilization systems since the early 20th century, autopilot functions are a long-established feature and the first drones in Germany are already in use in military, police and firefighting applications. Unmanned aerial systems or unmanned aerial vehicles (UAVs) are also used in civil applications in other countries, replacing for example ranchers and inspectors in remote areas. Drones monitor and seed fields and perform pest control functions. Small drones are already in use in Germany as well, for example for inspecting damage caused by storms or fires, in film productions and industrial inspections. Deutsche Bahn (the by far largest German railway company) is currently testing drones for monitoring vehicles and infrastructure. There are also pilot studies under way in the area of transporting commercial goods, in particular packages. With a carrying capacity of up to $2.5 \mathrm{~kg}$ and a range of approximately $15 \mathrm{~km}$, current 
drones could for example be used to deliver food or medications. A drone that can be used to transport a defibrillator has also been tested. The use of drones for commercial purposes over $5 \mathrm{~kg}$ has been generally permitted in many federal states, albeit not in controlled airspace [10].

Initial studies about unmanned maritime transport are currently under way (see e.g. the European research project MUNIN). Unmanned submarines have been used for some time. Concepts for drone ships are developed by various actors. One concept resembles platooning (see Sect. 18.3.4) in road traffic [11]. Here, in contrast to air traffic, it is possible to have crews boarding vessels at any time for example in heavily traveled areas such as the approaches to ports. As a rule, these systems will not act entirely autonomously, even not in the future. Although evasive maneuvers can be carried out independently, it can be presumed that centralized monitoring and remote controlling will remain standard practice, though the two instances need not be one and the same.

Remote control of driverless railway systems has been in place for years. Autonomous driving would include free navigation and would only be useful for very small units. To date, attempts to introduce smaller freight transport units on railways such as the CargoSprinter have been unsuccessful. In part, this is due to the fact that there is no fast technology for train composition, thus separate power transmission is required for each carriage. This deficiency was addressed with the RailCab concept [12]. Here, autonomous, linear motor-driven vehicles use the wheel and track system. The train composition is carried out through an electronic drawbar. This is expensive and there are few suitable applications in which a truck could not perform the transport. On the main carriage routes, efficiency gains through economies of scale speak against non-prescheduled routing and variable convoy formation. But there could be economically viable applications on non-electrified branch lines. To date, however, there are no known studies comparing the environmental and economic implications under market conditions.

\subsubsection{Interim Conclusion}

AGT systems consist of a guidance control system, in particular for order assignment and route planning, a communication system and the vehicles [4]. Automated guided transport systems and vehicles (AGTS/AGV) for in-house transport with low levels of automation have been in existence for a long time. The degree of automation has risen with advancements in technology, albeit in different ways than in public road transportation. For example, the applicable Machinery Directive for the design of such systems clearly defines the safety concepts. In the past it was sufficient for the AGTS/AGV in in-house logistics to be able to move in a forward direction, generally in sceneries in which people were accustomed to driverless vehicles. In some cases people and vehicles are physically separated. In sum, the safety concepts are restricted to a minimum as the AGT/AGV systems operate at low speeds and in known, clearly defined circumstances. 
Technological advancements focused on the correct execution of transport tasks and associated other tasks such as loading and unloading the cargo. Nevertheless, it may be presumed that the requirements with regard to the flexibility of AGT/AGV systems will rise as production moves away from linear assembly lines and the production and picking systems themselves become more flexible. At present, autonomous systems based on the agent technology seem best suited for the processing of increased data volumes and rising complexity, due to the decentralization of data provision and decision-making processes.

Outdoor solutions for freight transport are based on conventional road vehicles and to date have only been in regular use on private company grounds. There are only few use cases to speak of to date. But similar developments to the indoor area are generally conceivable.

The question with AGT/AGV systems then is how the autonomy of the units will develop in the future. Automatic control and driverless movement have by definition always been elements of AGT/AGV systems. The degree of autonomy is defined as the number of degrees of freedom. This depends, for example, on the free selection of the route and speed to move independently to a destination even in changing environmental situations.

The use of mobile machines represents a point of contact between work robots and vehicles. Just as with in-house transport systems, the transport task is frequently combined with other "productive" tasks. These are mostly remotely operated systems. Thus, autonomous decision-making in terms of route determination is generally not the case. This also seems unlikely to generate added value in the majority of possible applications.

In the early stages, the conceptual outline for automation solutions depended very strongly on the use context. These historical system elements are generally also found in the newer conceptual approaches, in particular with regard to the vehicle and operator safety concepts. It was only with the advent of decentralized concepts utilizing the new information and communication technologies that these different system solutions have been able to converge. In particular in situations in which high flexibility and speed are demanded, the technological solutions are becoming increasingly similar. They do differ in terms of the degree of autonomy, though.

\subsection{Use Cases in the Field of Autonomous Freight Transport}

Building on the experiences described here, the following will sketch potential applications for autonomous vehicles in the field of freight transport using the generic use cases described in Chap. 2. The focus is on the transport of a specific good in road freight traffic. Potential applications in further segments of commercial transportation such as passenger transportation and goods transport in the context of production (self-driving work machines) are not examined here.

Based on a conceptual description of the respective use case and in light of the specific features, an initial estimation of the benefits, opportunities and risks of introducing such a 
technology will be discussed. The examination will begin, however, with a consideration of the degrees of automation in driving for freight transport, in order to better distinguish the implications of the various use cases.

\subsubsection{Excursus: Degrees of Automation in Autonomous Freight Transport}

To assess the necessity and benefits of a certain degree of automation in freight transport, first we will return to the definition of the driving task according to [13], whereby it is described as follows: The safe execution of the driving task requires information and knowledge regarding the traffic situation on the guidance level, the driving surface on the stabilization level, as well as the road network on the navigation level. Safe conduct of the vehicle requires steering, acceleration and braking as well as decisions regarding speed and course for longitudinal and lateral control of the vehicle. The decisions required for this are made on the basis of information regarding environmental conditions and the associated knowledge of the action to be taken.

The German Federal Highway Research Institute categorizes automated driving into four development levels [14]: assisted driving (1), partially automated driving (2), highly automated driving (3) and fully automated driving (4). In the first three levels, the system performs partial aspects of the driving task for a specific time and/or in specific situations. But the driver is available at least as a supervisory organ. For the last level of fully automated driving (4), [14] presumes that the vehicle is navigating freely and no driver is required as a fallback level.

In the area of freight transport, automated guided transport systems exist even on low automation levels. With an intermediate level between (3) and (4), another relevant variant in transport practice can be observed: The vehicle is highly automated and driverless, but free navigation does not occur. In many cases, the vehicle is controlled remotely by an operator via a control center.

\subsubsection{Use Cases for Autonomous Freight Transport}

Assisted and partially automated systems are already common in series-production vehicles. They take over longitudinal and/or lateral control of the vehicle for a certain period of time and/or in specific situations. In the assisted systems, the driver is warned; in partially automated systems, the system assumes control. The impetus-for example braking - must still be provided by the driver. The most well-known driver assistance systems (DAS) are anti-lock brake systems (ABS) and electronic stability programs (ESP). Due to severe road accident, lane-change assistants, lane-departure warning systems and adaptive cruise control functions became mandatory for new vehicles ahead of schedule in 2013. Other systems are in development or are already ready for production, 
such as anti-rollover systems, cornering systems or parking systems. They are primarily focused on assisting the driver on the guidance and stabilization levels.

Highly and fully automated vehicles can also navigate freely; they are situation- and infrastructure-independent. Fully automated systems can function without a driver. Not only activities on the navigation level are assumed by the driving robot, but also the activities that are necessary to return the system to a minimal-risk state when components fail.

From the perspective of freight traffic and logistics, technological solutions for the stabilization and guidance levels are therefore not the primary focus. Of greater interest are the potential use cases with and without drivers and free navigation. A closer examination is conducted on the following distinctions in the use cases:

1. Interstate Pilot as highly automated highway driving with a driver and free navigation;

2. Vehicle On Demand as highly automated highway driving without a driver and with free navigation;

3. Full Automation Using Driver for Extended Availability-Follow-me Vehicle as highly automated driving without a driver and without free navigation (missing use case 3/4),

4. Valet Parking as highly automated driving without a driver and without free navigation (missing use case 3/4).

In the following, the use cases will be introduced and initial arguments for and against the respective degree of autonomy in logistics and freight transport are presented. In each case it will be assessed to what extent the use cases in the freight traffic system coincide with the "Use Cases of Autonomous Driving" (see Chap. 2) for private transportation, what differences exist and what the implications of such differences are for implementation.

\subsubsection{Interstate Pilot with Driver and Free Navigation}

Interstate pilot describes the use case in which an autopilot function is used, but a driver is available at all times. The driver hands over the stabilization and guidance level (and thus also navigation) to the autopilot, ideally after specifying a destination address. The use of an interstate pilot is intended between entering and exiting the interstate. The driver assumes control when confronted with unclear driving situations (e.g. construction zones).

The posited benefits of the interstate pilot are provided by the reduction of accidents and an improved traffic flow. Particularly in traffic jams or stop-and-go traffic situations, but also on long, monotonous journeys, as well as due to the ever-increasing time-pressure of modern life, drivers are often close to their performance limits. In addition to unburden the driver from stressful driving situations, the interstate pilot also creates free time that 
can be used for other purposes. Here there are deliberations as to whether activities such as route planning and fleet management might not also be decentralized.

A first case of application has been already reported from as early as 1987, when the University of the Armed Forces in Munich, Germany, was experimenting with a lorry driving on a motorway [15]. In 2013, the vehicle-manufacturer Scania presented a truck that could "independently accelerate, brake and steer" up to a speed of $50 \mathrm{~km} / \mathrm{h} \mathrm{[16].} \mathrm{In}$ 2014, Daimler had a truck driving up to $85 \mathrm{~km} / \mathrm{h}$ amid other vehicles on a closed section of interstate [17].

The envisioned interstate pilot is essentially enabling fully automated driving. Due to safety considerations, however, the concept still depends on an available driver, which in effect reduces the scenario to being only highly automated. The effective top speed and the higher maximum permissible mass together require different safety concepts than in private transportation.

Changes are expected primarily in terms of the job description of the driver. To date, drivers have been obliged to learn much about vehicle technology and securing loads. Would the driver continue to perform the technical inspection of the vehicle? What economic and environmental benefits would be associated with the concept?

\subsubsection{Vehicle on Demand Without a Driver and with Free Navigation}

Vehicle on demand most closely resembles the use case, which, in the field of freight transport, is known as an autonomous, decentralized AGT/AGV system. A driver's seat is not envisioned. However, in the use case outlined in Chap. 2 the vehicle can operate at speeds of up to $120 \mathrm{~km} / \mathrm{h}$ and in unknown scenarios.

There is some reason to believe that the "vehicle on demand" use case comes very close to the conception of autonomous vehicles in freight transport desired by companies in the industry: The local-language-speaking driver who is willing to undertake long interstate journeys with long periods of absence and irregular working hours for low pay is ever-more-difficult to find. Overtired truck drivers are the most common cause of severe accidents. Docking and maneuvering in tight delivery situations is always a tricky task for the driver.

The use of automation technology could therefore be of great benefit. However, the approval of all scenarios for heavy trucks will take time, in particular due to safety concerns and required changes in the supply chain (see Sect. 18.4).

More likely is the realization of the interstate pilot without a driver and with free navigation between rendezvous points in the medium term, for example between rest areas on highways or between well-connected commercial zones. The likelihood of implementation of this use case could be increased through the following enhancement concepts: 
Safety concerns due to the lack of a driver on the fallback level could be mitigated by having separate highway entrances and exits for autonomous vehicles, as this would reduce encounters with other vehicles to a minimum. A dedicated lane for autonomous, coupled vehicles could probably avoid these concerns entirely. At the same time, such a dedicated lane could be the starting point for an extended concept with alternative drive technology, if the lane were, for example, outfitted with an overhead contact line for supplying electricity.

The coupling of vehicles (platooning) would combine the initial concept of having a driver available in the lead vehicle as a backup with the extended concept in which vehicles drive autonomously without drivers and utilize the benefits of each concept. The platooning vehicles would be connected via a software system. Implementing the so-called electronic drawbar at high speeds would enable not only improved utilization of the road infrastructure, but above all reduced fuel consumption and emissions due to reduced wind resistance.

Numerous tests have been carried out with the electronic drawbar since the mid-1990s [e.g. the European projects "CHAUFFEUR I and II", "Safe Road Trains for the Environment (SARTRE)", "Cooperative mobility solution for supervised platooning (COMPANION)", the Californian "PATH Program", the German "KONVOI-Projekt: Entwicklung und Untersuchung des Einsatzes von elektrisch gekoppelten Lkw-Konvois auf Autobahnen", and the Japanese "ITS Project" by the New Energy and Industrial Technology Development Organization (NEDO)]. In these projects, multiple trucks or a convoy of lead trucks and following passenger cars safely drove at up to $90 \mathrm{~km} / \mathrm{h}$ with a minimum gap of $4 \mathrm{~m}$. The systems were based on surveillance by radar sensors, stereo cameras, three-dimensional maps and usually also data exchange with other vehicles. Previous trials were always conducted with a driver in the lead vehicle and with or without drivers for extended availability in the following vehicles. There are already ideas under consideration for a driverless lead vehicle.

As a rule these projects build on proven existing technology: adaptive cruise control systems integrated in series-production vehicles serve to maintain the gaps between the vehicles. Data transmission between the lead and following vehicle is frequently conducted via wireless-transmission or infrared technology.

The measured fuel savings and $\mathrm{CO}_{2}$-reduction potential differed depending on the selected vehicle-to-vehicle (V2V) communication (in "off-center" mode), the type and construction of the lead vehicle and following vehicles, the gap, the speed as well as the road and environmental conditions (surface, temperature, inclines, altitude). The difference was roughly $5 \%$ for the lead truck and $10-15 \%$ for the following passenger vehicles [18]. 


\subsubsection{Full Automation Using Driver for Extended Availability- Follow-Me Vehicle}

In the use case presented in Chap. 2, the vehicle takes fully automated control whenever the situation is approved for that mode. The driver is at any time available and can resume vehicle control if necessary. In practice it is an extension of the interstate pilot in terms of approved situations and the permissible speed and is very similar to autonomous driving.

This use case is only interesting from an economic perspective if the accompanying driver can pursue value-creating activities during the drive. The next delivery could be prepared or processed from an administrative standpoint during the drive itself. Such vehicle concepts would also be conceivable for use in commercial passenger traffic, for example for activities in elderly care, the insurance industry, etc., which involve documentation and administrative work.

The "EmiL" concept study of a partially autonomous delivery vehicle in 2011 can be regarded as a sort of preliminary stage of development before full automation [19]. In this concept, the delivery person does not need to continually get in and out of the vehicle, but can instruct the vehicle via mobile phone to drive next to him at walking speed (follow-me function). For all unknown situations (e.g. merging situations, intersections), there is the additional DriveStick mode in which the vehicle can be driven at up to a speed of $6 \mathrm{~km} / \mathrm{h}$. The use of a local wireless-connection precludes signal interruptions that are feared and can indeed occur with GPS connections.

The research project determined a time-saving of about 40 min over a one-day delivery period. The typical injury risk of twisting or rolling an ankle when getting out of the vehicle is also reduced.

\subsubsection{Valet Parking —Valet Delivery}

Valet parking refers to the use case in which the autopilot independently navigates the vehicle to a previously assigned parking spot. The concept presented in Chap. 2 assumes that this could be possible in the public sphere at speeds of up to $30 \mathrm{~km} / \mathrm{h}$. One example could be autonomous driving from a driver's place of residence to a defined parking spot. This use case is scarcely conceivable in the context of freight transport, however, as there are truck-parking locations rarely connected via the secondary road network.

Much more likely is a scenario in which the autopilot would take over in tight inner-city areas and industrial and retail delivery zones not designed for large trucks and park or dock the truck independently. This could prevent expensive car damages to occur. The driver would be relieved of stressful driving tasks, which would be particularly advantageous in light of the driver's remaining responsibility for long, exhausting highway drives. Valet delivery could also help drivers comply with legal rest times if the "last mile" could be conducted without their assistance. 
Another potential use case could be delivery to construction sites. In major construction jobs, trucks are increasingly held in so-called waiting zones in the vicinity of the construction site. These processes could be optimized if drivers in large-scale concrete-pouring actions could concentrate on their runs and the wait times were eliminated. The autopilot would take over driving between the waiting point and the construction site.

From a legal standpoint, implementation would depend heavily on the distance between the waiting point and site as well as the concrete scenario. Otherwise implementation would seem to be more of a mental than a technical challenge. In particular from the driver's perspective, who would be confronted with scenarios in which it is essentially alleged that he or she does not handle their working tool with the required skills.

\subsection{Changes in the Supply Chain Resulting from a Higher Degree of Automation in Freight Transport}

A systematic examination of the changes in the supply chain resulting from a higher degree of automation in freight transport can be seen in the generic supply chain depicted in Fig. 18.1. Every supply chain consists of a succession of the activities "raw material extraction", "processing/production", "trade", and the intermediate logistical processes "goods issue (handling)", "transport", and "goods receipt (handling)". Moreover, under the current conditions of production and retail logistics, it is equally interesting to consider the effects of a lacking driver since a lot of added-value-services are performed by the logistics providers in those scenarios.

Aside from driving itself, "transport" requires inspection of the vehicle, route planning as well as documentation and other administrative tasks (shipping documents) taken over by the driver. These activities are even more comprehensive in the case of cross-border traffic (customs). With highly automated, driverless or fully automated driving, the common problem of driving and rest-period violations would become obsolete and routes could be planned differently. If transports were conducted in a highly-automated manner, the driver would be expected to perform other tasks in this period, for example performing route planning, fleet management or simply resting [21].

In other words, it could lead to both a decentralization and parallelization of functions. The use of the transport time for other activities is not new, however. For example, postal shipments were previously handled in trains (postal trains), and the same phenomenon can be observed today, in mobile depots (e.g. repurposed double-decker buses, "floating warehouse systems").

The driver must always supervise the driving task and sometimes takes over personally. At the goods issue point, he or she is responsible for checking the shipping papers and securing the load. At the goods receipt point, he or she is responsible for demanding a receipt confirmation. 


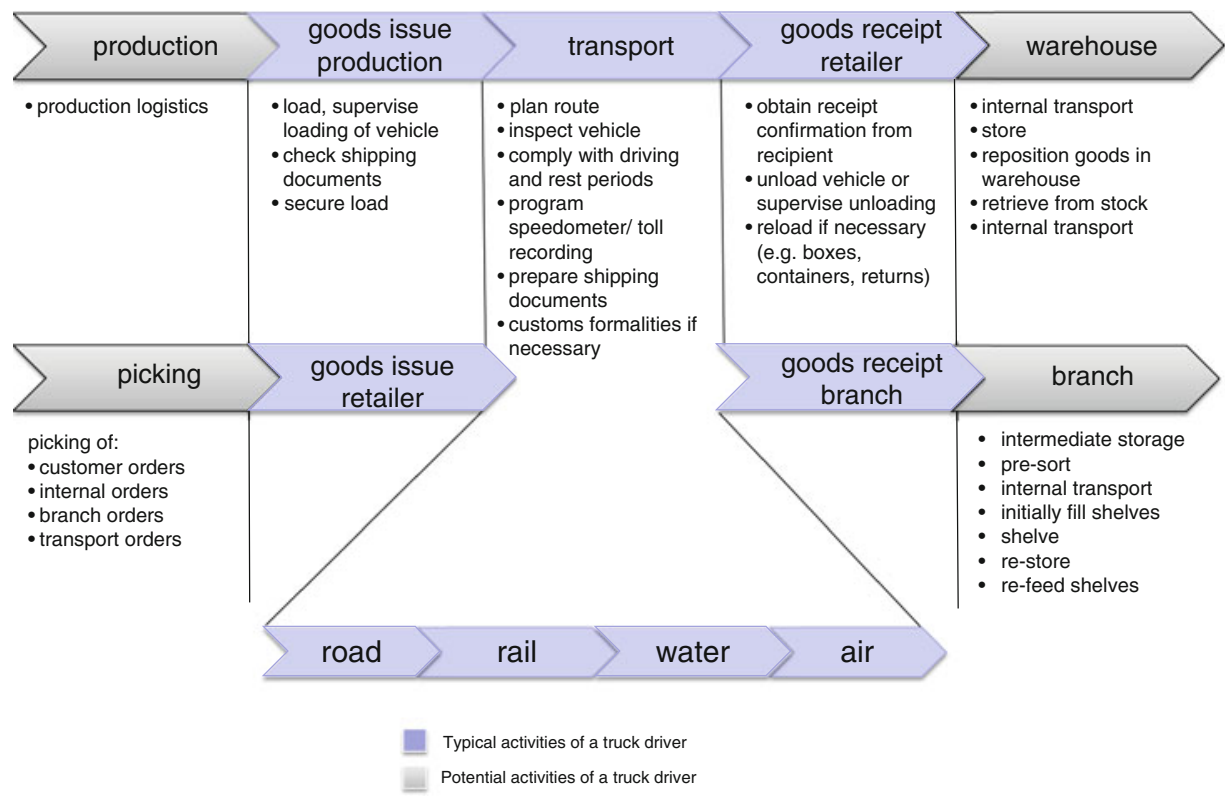

Fig. 18.1 Example of driver-relevant activities in a generic supply chain. Source Author, based on [20]

Today, in goods issue and receipt, in many supply chains the driver is responsible for loading and unloading the vehicle. The driver's responsibility frequently ends at the loading ramp, but in some cases only after placement of the goods in the receiving facility, or even after pre-sorting, internal transport and shelving of the material (in some cases in temporary storage locations). As in earlier times, for some parcel and letter delivery operations it is common for the driver to pick the orders himself.

In the field of production, conceivable applications would include own-account transport in which - similarly to the in-house segment - transport jobs are tendered and autonomous trucks could "apply" for and win the transport jobs based on predefined criteria. In this case neither a central control function nor route determination is required. Some gates already have freight locks, making workforce obsolete in place at the transfer of risk.

If the driver no longer "accompanies" the vehicle, his or her activities would have to be performed by others. Companies then would have once again to hire or train own staff for such activities. The logistics companies might also opt for a different business model to account for these changes. This could lead to a general revaluation of work and the creation of local jobs, particularly in urban areas. In other cases, however, a further increase in the degree of automation in goods receipt and issue departments could be envisioned. 
Changes in the transport systems themselves can be expected primarily at the contact points between unmanned and manned driving as well as in the task profile of drivers. The changes to processes in rail and maritime traffic as well as in the spectrum of activities performed by humans do not seem overly serious. The driver is removed from the scenario and replaced by an autopilot. The remaining technology in trains and ships has heretofore been excluded from any proposed changes. Also, new job descriptions could emerge, for example if the aspect of security against pirates in sea transport were to be given greater weight than the navigation aspect.

\subsection{Initial Microeconomic Assessments of Automated Systems in the Freight Transport Chain}

From a microeconomic perspective, a lack of driving personnel, an energy-saving driving style, high reliability and accident evasion are significant reasons to employ autonomous systems in the freight transport chain. In some industries, the material flow from goods receipt to the production lines and eventual goods issue are already highly automated and driverless, which eliminates interruptions and idle times. Loading and unloading from warehouses is also highly automated and driverless in some sectors. In some cases, the control of warehousing and production is coordinated and ranges from automated goods receipt to automated goods issue.

The development of radio frequency identification (RFID) technology and the rediscovery of Leonardo da Vinci's idea of learning from nature (bionics) inspired a debate on independent control and led to an intensive debate on the decentralization and decision-making autonomy of technical systems. Aided by technological developments in cost-effective sensors and internet-aided software systems, the degree of automation has risen continuously. The latest systems in production and warehouses have come to rely on independent control ("internet of things") of the vehicles and conveyor systems, which can react autonomously to changing requirements, states and environmental conditions.

Based on the extremely advanced degree of automation of in-house AGT/AGV systems in some industries, further shifts of the human role towards conceptual and supervisory activities can be expected. The use of driverless vehicles in the entire logistical system can be expected to lead to a reorganization of processes in many supply chains (see Sect. 18.4). However, automation will continue to grow only in particular industries as the relation between costs and benefits is not equally favorable in all sectors.

Within the transport system in the public space, the lack of a driver and/or the driver's changing role will lead to additional interfaces that need to be designed according to certain requirements. The driver getting in and out of the vehicle requires additional stops. In the in-house field, there is already substantial experience to draw upon, for example, with regard to picking. In the traffic systems, such experience is limited. In maritime shipping, for example, it is quite common that a port skipper is taking over active control 
of the ship when entering the port area. In the road freight traffic system, the predominant transshipment systems generally involve changing the trailer rather than the driver. These systems have many advantages such as quick transfer times for materials and goods, and results in increasing productive times of the vehicles. They also improve the working conditions for the drivers, who can return to their local branches daily. In practice, however, this only works in large networks or in partnership-type relationships with trustworthy and reliable partners. This applies not only to punctuality, but also with respect to the securing of the load. To date, the most widespread use of these systems has been with the large integrators and courier, express and parcel (CEP) service providers specialized on the transshipment of standardized packages.

For the implementation of driverless transport chains in road freight transport, then there are also questions of cost and liability in transport law that need to be clarified, going beyond questions of technical compatibility of the autonomous vehicles with the infrastructure and with other vehicles or platooning trucks.

If damages to the goods or vehicle occur due to system failure, product liability comes into play (for details, see Chap. 25). It follows that autopilots, consisting of hardware components (sensors, processors and actuators) and software components must be constructed in such ways that potential damages can be traced to the individual components and thus their producers.

\subsection{Initial Macroeconomic Assessments of Automated Systems in the Freight Transport Chain}

Judging from a macroeconomic perspective as well, automated systems could provide an approach to resolve structural deficits in the current transport system. In times of tight public budgets, a significant expansion of the traffic infrastructure, and in particular rail and inland waterways, is not likely to occur in the near future.

Automated driving, with its minimal space requirements and rather equal speed levels, could at least double the existing average road infrastructure capacity. Moreover, it could contribute to achieving environmental policy goals, as automated driving reduces fuel consumption. Already today, driver assistance systems make a significant contribution to reducing traffic accidents. Such accidents could also be avoided by the use of highly and fully automated vehicles, as they can recognize the ends of traffic jams, avoid risky overtaking maneuvers and entirely eliminate wrong-way driving. However, the questions concerning legal liability in the event of an accident have not yet been exhaustively resolved.

In the case of platooning, a professional driver could be used in the lead vehicle, as is envisioned in most of the projects. This approach has the advantage of enabling even unpracticed long-haul drivers (beginners, the elderly) to join a convoy. This would also require that freight and passenger vehicles have the ability to communicate with each other. 
However, it is not only technological determinism that offers strong arguments against automated road vehicles: Efficiency increases in road traffic also give rise to conflicts with mass transport systems. Automated platooning stands in direct competition with the railways, as did long trucks before them. Although at present there is a lack of professional truck drivers in Germany, the overall number of professional truck drivers would decrease, and in other countries with high unemployment, much-needed jobs would be lost.

Moreover, public acceptance of fully automated systems is limited-not least due to continuous reports of failures of mechanical or electronic components in vehicles, or the fear of unstable data connections. Autonomous vehicles therefore would also have to be equipped with reliable software (artificial intelligence) that can respond to all eventualities - in particular when humans and animals are present on the roads.

Also judging from a legal perspective, autopilots outside of factory grounds are a novelty. Previous AGT/AGV systems were handled according to the Machinery Directive, with stringent vehicle and operator safety concepts. An expansion of the sphere of action (private/public) and the operating speeds (walking speed to highway speeds) of the systems could necessitate new laws or adjustments to the existing legal framework.

The use of autonomous vehicles in road traffic would require abolishment of the legal restrictions set forth in the Vienna Convention on Road Traffic which stipulates that a driver must maintain control over the vehicle at all times. There have been recent developments in this regard in the United States, where the law has been adapted to permit deviation from the control requirement insofar as the system "can be overridden or switched off by the driver." If this legal stance were to be accepted in Europe as well, it would mean that there has to be a superordinate actor that can always intervene in controlling the vehicle. In the areas of rail, maritime and air traffic, the systems are already designed in this manner, and for rail and air traffic there are accepted superordinate actors. For road freight traffic, such an actor must still be created. Public acceptance is also yet to be ensured.

\subsection{Conclusion and Outlook}

Since the 1960s, (driverless) automated guided transport (AGT) systems have been in use in in-house logistics in Germany. However, these systems have not received sufficient attention either in the media or in transport research. In in-house logistics, for example, transponders are used as waypoints that can also store information. If vehicles in the public space would always have to recognize all environmental features and special characteristics of every route, appropriate cost-intensive hardware and software systems would be required. This could be avoided if waypoints would provide certain information that could be read-out temporarily. In this context, extrapolated to the transport system, the question arises as to how the road infrastructure would have to be changed. 
Fully automated driving creates the opportunity to steer vehicles between the departure point and the destination without human intervention. The autopilot performs not only the stabilization and guidance tasks, but also navigation, and thus is also responsible for ensuring accident-free driving.

The assessment of the current situation with respect to the development of autonomous road traffic systems made clear that passenger and freight traffic must be viewed in a much more integrated fashion. It would also be interesting to have a closer look at autonomous system development with regard to other means of transport. Autopilots in aircrafts have long been the norm. As early as the beginning of the twentieth century, stabilization systems were used in aviation. Drones are already being used. The first studies on the European level of unmanned maritime transport are under way. Remote control of trains has been in use for years as well. What is new is the quality of autonomous decision-making in the case of changing environmental situations and changing driving and transport orders. The expanding fields of application, for instance through drones in the aviation sector, highlight the importance of completely rethinking the distribution of transport jobs across the different means of transportation. More research is needed here.

Many exciting insights and new developments could be expected if the broad field of commercial passenger traffic would be studied in greater detail. Much alike in freight transport, it is concerned with mobility in exercising a profession. Since moving from one location to another is only a means to perform a service at the destination, in most cases mobility itself is regarded much more pragmatically, compared to individual mobility.

The combination of partial scenarios of individual, autonomous logistics processes to form a comprehensive autonomous supply chain from automated raw material extraction and all phases of production and logistics to product delivery to the end customer requires an integrated approach. Technologically speaking, tremendous progress has been realized in recent years. Research should therefore focus primarily on the (required) degree of automation for individual logistics processes as well as on elucidating the micro-and macroeconomic benefits and costs of those developments.

Due to the open legal questions and the lack of acceptance of both the general public and to some extent of corporate decision-makers for the use of autonomous systems in road freight transport (as well as to some extent in other transport systems), gradual, step-by-step introduction seems to be the only realistic approach. It will therefore depend on finding the right cascade approach and implementation strategy. To date, specific deliberations on the respective implementation aspects of the outlined use cases are missing.

On first glance, it appears reasonable to combine some of the solution approaches currently being discussed with regard to increasing the capacity of the infrastructure, economical use of resources and environmental protection. Starting to introduce autonomous driving in closed transport systems (e.g. transport in system cooperation) and manageable scenarios (e.g. interstate, airport grounds, ports) will help to overcome reluctance concerning the technologies as well as lacking standardization. The 
step-by-step implementation of platooning, starting with manned lead and following vehicles, could build the requisite acceptance among the general public. It must be examined whether the simultaneous introduction of overhead electricity-powered trucks and thus the creation of a dedicated lane would be sensible in view of capacity and safety requirements.

However, even platooning raises several follow-up questions, in particular regarding decision-making and the distribution of benefits: If the fuel savings depend on a vehicle's position in the convoy, who decides which position each vehicle has in the chain? If the convoy drove without drivers in the following vehicles, who would pay for the driver in the lead vehicle? Would the lead driver require more/special training than the other drivers? Prior to introduction, it would also be necessary to clarify how other platooning vehicles can be identified. A common standard would have to be developed to ensure that the other vehicles are also trustworthy. Here the need for further study and the recommendations for action are closely interrelated.

Changes in the supply chain and freight transport show a highly ambivalent picture that must be examined in greater detail. For the relating understanding, assessment and categorization, it must be clarified which technological changes and challenges will arise for the driving task itself. It is also essential to identify in greater detail the advantages and disadvantages of using automated vehicles compared to conventional vehicles as well as their integratability in the existing work environment, by analyzing different job profiles in the commercial environment. To date, the question of what can be transported autonomously and what degree of autonomy would be accepted from industry with regard to necessity, cost and flexibility remains unanswered.

At the same time, there are also additional opportunities for innovative business models, which, however, have yet to be developed and evaluated. Also alternative applications are conceivable whose challenges until today seemed unsurmountable. One example of this is the provision of supply and disposal services to inner-city locations ("city logistics"), which is characterized by conflicts and high costs. The use of autonomous road transport vehicles, together with other components (e.g. goods lock system) could for instance resolve temporal conflicts between freight and passenger traffic.

At the same time, the opportunities and risks associated with the rising automation of transport should be analyzed in greater detail from a macroeconomic, cross-border perspective. This includes not only legal matters and the need for standardization, but also the potential loss of low-level jobs. This must be analyzed in terms of alternative labour-market scenarios. Also, to date insufficient attention has been paid to the conflicts that could potentially arise between autonomous road freight transport (in convoys) and means of mass transportation. Finally, the discussion must be expanded thematically, in order to achieve the best comprehensive assessment of environmental and resource considerations. 
Open Access This chapter is distributed under the terms of the Creative Commons Attribution 4.0 International License (http://creativecommons.org/licenses/by/4.0/), which permits use, duplication, adaptation, distribution and reproduction in any medium or format, as long as you give appropriate credit to the original author(s) and the source, a link is provided to the Creative Commons license and any changes made are indicated.

The images or other third party material in this chapter are included in the work's Creative Commons license, unless indicated otherwise in the credit line; if such material is not included in the work's Creative Commons license and the respective action is not permitted by statutory regulation, users will need to obtain permission from the license holder to duplicate, adapt or reproduce the material.

\section{References}

1. Vahrenkamp, R.: Von Taylor zu Toyota: Rationalisierungsdebatten im 20. Jahrhundert. 2. korrigierte und erw. Auflage. Josef Eul Verlag: Lohmar-Köln (2013)

2. Ullrich, G.: Fahrerlose Transportsysteme. 2. Auflage, Springer Fachmedien, Wiesbaden (2014)

3. Ullrich, G.: Effizientes Fulfillment mit Fahrerlosen Transportfahrzeugen. DS Automotion. http:// www.ds-automotion.com/uploads/tx_sbdownloader/hermes.pdf (2012). Accessed: July 4, 2014

4. Schwarz, C., Schachmanow, J., Sauer, J., Overmeyer, L., Ullmann G.: Selbstgesteuerte Fahrerlose Transportsysteme - Self Guided Vehicle Systems. Logistics Journal (2013). doi: 10. 2195/lj_NotRev_schwarz_de_201312_01

5. Sauer, J., Ullmann, G.: Schlussbericht zu dem geförderten Vorhaben 17237 N. Dezentrale, agentenbasierte Selbststeuerung von Fahrerlosen Transportsystemen (FTS). Bundesvereinigung Logistik e.V.. http://www.bvl.de/files/441/481/17237_Schlussbericht_FTS-Selbststeuerung_ 20131002.pdf (2013). Accessed: July 27, 2014

6. Hamburger Hafen und Logistik AG: Wer hat's erfunden? Hamburger Hafen und Logistik AG. http://hhla.de/de/container/altenwerder-cta/das-projekt-agv.html (2014). Accessed: July 2, 2014

7. Dermuth, R.: Fahrerloser LKW in einer Molkerei. GÖTTING. http://www.goetting.de/news/ 2012/molkerei (2013). Accessed: July 2, 2014

8. Kerner, S.: SaLsA - Sichere autonome Logistik- und Transportfahrzeuge. Fraunhofer IML. http://www.iml.fraunhofer.de/de/themengebiete/automation_eingebettete_systeme/Forschung/ salsa.html (2014). Accessed: June 27, 2014

9. Komatsu Ltd.: Autonomous Haul System (AHS). Komatsu Ltd. http://www.komatsu.com.au/ AboutKomatsu/Technology/Pages/AHS.aspx(2005). Accessed: July 2, 2014

10. Wirth, N.: Zivile Drohnen heben ab - auch an der Börse? Trendlink.com. http://www.trendlink. com/aktienanalysen/aktien/zivile_Drohnen/78-Zivile_Drohnen_heben_ab_-_auch_an_der_ Boerse (2014). Accessed: July 22, 2014

11. Hegmann, G.: Rolls Royce glaubt fest an Drohnenschiffe. Welt.de. http://www.welt.de/ wirtschaft/article123352845/Rolls-Royce-glaubt-fest-an-Drohnenschiffe.html (2013). Accessed: July 30, 2014

12. Böcker, J., Henke, C., Rustemeier, C., Schneider, T., Trächtler A.: Rail Cab - Ein Schienenverkehrssystem mit autonomen, Linearmotor getriebenen Einzelfahrzeugen. Universität Paderborn. http://wwwlea.uni-paderborn.de/fileadmin/Elektrotechnik/AG-LEA/ forschung/veroeffentlichungen/2007/07ETG_Henke_Rustemeier_Schneider_Boecker_ Traechtler.pdf (2007). Accessed: July 30, 2014

13. Donges, E. 1982. Aspekte der Aktiven Sicherheit bei der Führung von Personenkraftwagen. Automobil-Industrie, 2, pp. 183-190

14. Gasser, T.M.: Rechtsfolgen zunehmender Fahrzeugautomatisierung. Berichte der Bundesanstalt für Straßenwesen 83. (2012) 
15. Please see the related video available under http://dyna-vision.de/ to be found in section hardware used 2.3 Van VAMoRs of the directory.

16. Brünglinghaus, C.: Scania erforscht das automatisierte Lkw-Kolonnenfahren. Springer für Professionals. http://www.springerprofessional.de/scania-erforscht-das-automatisierte-lkwkolonnenfahren/4909638.html (2014). Zugegri. Accessed: July 4, 2014

17. Grünweg, T.: Autonom fahrender Lkw: Laster ohne Lenker. Spiegel Online. http://www. spiegel.de/auto/aktuell/autonome-lkw-neue-technik-soll-fernfahrer-entlasten-und-sprit-sparen-a978960.html (2014). Accessed: July 4, 2014

18. Tsugawa, S.: Energy ITS: What We Learned and What We should Learn. Onlinepubs.trb.org. http://onlinepubs.trb.org/onlinepubs/conferences/2012/Automation/presentations/Tsugawa.pdf (2012). Accessed: July 30, 2014

19. Bundesministerium für Umwelt, Naturschutz und Reaktorsicherheit (Hrsg.): Abschlussbericht zum Verbundvorhaben Erprobung nutzfahrzeugspezifischer E-Mobilität - EmiL. erneuerbar-mobil.de. http://www.erneuerbar-mobil.de/de/projekte/foerderprojekte-aus-demkonjunkturpaket-ii-2009-2011/wirtschaftsverkehr-feldversuche/abschlusberichtewirtschaftsverkehr/abschlussbericht-emil.pdf (2011). Accessed: July 2, 2014

20. Bieber/Deiß 2000 Bieber, D.: Schnittstellenoptimierung in der Distributionslogistik: innovative Dienstleistungen in der Wertschöpfungskette. SSOAR. http://www.ssoar.info/ssoar/bitstream/ handle/document/9993/ssoar-2000-bieber_et_al-schnittstellenoptimierung_in_der_ distributionslogistik.pdf (2000) Accessed: July 17, 2014

21. Daimler AG: Weltpremiere: Daimler Trucks präsentiert mit autonom fahrenden „Mercedes-Benz Future Truck 2025“ den Lkw der Zukunft. daimler.com. http://www. daimler.com/Projects/c2c/channel/documents/2495102_Daimler_IRRelease_03072014_de.pdf (2014). Accessed: July 4, 2014 